\title{
Active Power Filter for Single-Phase Quasi-Z-Source Integrated On-Board Charger
}

\author{
Tuopu Na, Qianfan Zhang, Jiaqi Tang, and Jinxin Wang
}

\begin{abstract}
Single-phase quasi-Z-source rectifiers have second harmonic currents and corresponding ripple voltages on the dc bus. To filer the voltage ripple, bulky capacitor bank is needed. This paper proposed an active power filter (APF) for single-phase quasi-Z-source rectifier. It eliminated the second harmonic power with small capacitor and inductor. This topology is suitable to integrated electric vehicle (EV) on-board charger, which can use EV's inverter hardware as its own rectifier hardware. Thus, this proposed topology can save much space and weight. Simulation and experimental results verified the proposed system.
\end{abstract}

Index Terms-Active power filter, integrated charger, quasi-Zsource, single-phase rectifier.

\section{INTRODUCTION}

$\mathrm{E}$ LECTRICAL vehicles (EVs) have been widely used recently. The charger of EVs plays an important role in EVs system. An onboard charger makes it convenient for customers to charge. Thus, an onboard charger is necessary for EVs. An integrated onboard charger is proposed in [1]. The integrated charger and the EV's traction system share the hardware including three IGBT bridges, circuits and sensors. Besides, the integrated charger uses motor windings as filter inductor. The integrated charger costs less and takes less space. The quasi-Z-source network is suitable for single-phase integrated charger because it can realize bi-directional power flowing.

Since single-phase PWM rectifier has dc-side second harmonic current, it needs not only larger dc-side capacitor but also larger quasi-Z-source inductor and capacitor to suppress ripple. These inductors and capacitors will increase the charger's weight and take much space. And the dc-side second frequency ripple will reduce the battery life. So it is necessary to eliminate second frequency ripple. Many APFs [2]-[10] have been proposed to solve the problems for traditional single-phase converters. APF uses auxiliary circuit to convert the ripple power from the dc link to other energy storage components. [10] uses an inductor as energy storage, which includes one bridge circuit and one inductor. [6] also uses inductor as energy storage. In this system, a third IGBT bridge is added and one inductor is used which cost much. Capacitor is also can be used as energy storage for APF. [9] proposed a topology which adds a third IGBT bridge, a capacitor and an inductor. Two capacitors are used as energy storage in [8]. These APFs are suitable for single-phase

Manuscript received July 31, 2018.

The authors are with Harbin Institution of Technology, Harbin, China (email: natuopu@126.com; zhang_qianfan@hit.edu.cn; tang_jiaqi@ outlook.com;1141420310@hit.edu.cn).

Digital Object Identifier 10.24295/CPSSTPEA.2018.00019

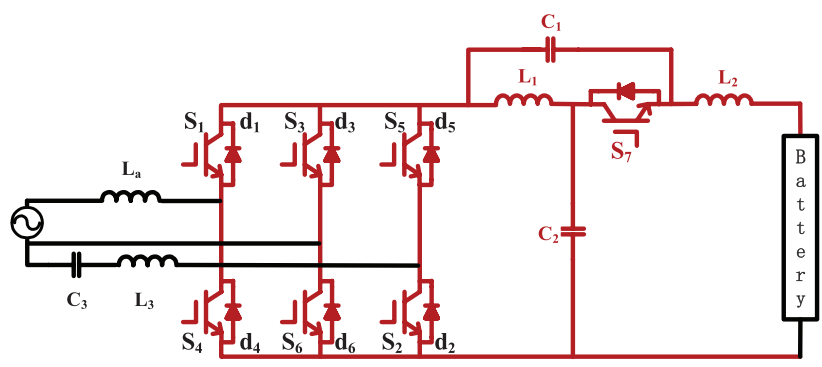

Fig. 1. The topology of single phase quasi-Z-source integrated charger with APF control.

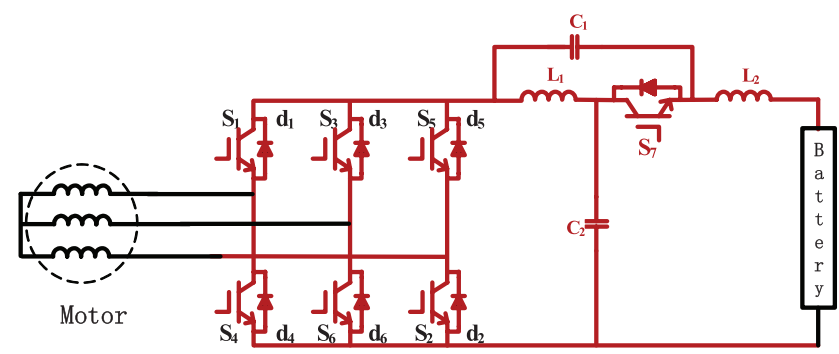

Fig. 2. The topology of EV traction system.

PWM rectifier, and some methods have been proposed to solve the second harmonic current in single-phase z-source inverters [11]-[13].

However, there is not a method proposed for single-phase z-source PWM rectifier. In this paper, a topology is proposed for eliminating the second harmonic current of the system, as shown in Fig. 1. And this topology is suitable for single-phase $\mathrm{EV}$ on-board integrated charger. The proposed topology uses extra IGBT S5 and IGBT S2 to control C3 and L3 to absorb the second harmonic power. The traction system of one electric vehicle is shown in Fig. 2. So the proposed APF single-phase Z-source rectifier can use three IGBT bridges and the quasi-Zsource network to eliminate the second harmonic. The red topologies in Fig. 1 and Fig. 2 share the hardware including three IGBT bridges, quasi-Z-source network and control circuits. The integrated single-phase on-board charger saves much space, costs less and reduces weight.

\section{Proposed APF Single-Phase Quasi-Z-Source RECTIFIER}

\section{A. Existing Problem Analysis}

The topology of traditional single-phase quasi-z-source rectifier is shown in Fig. 3. With PFC, the grid-side voltage and cur- 


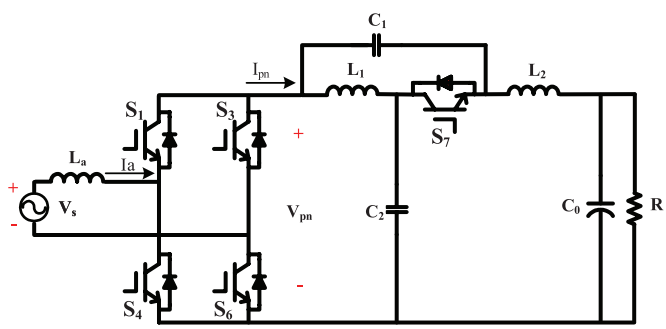

Fig. 3. The traditional quasi-Z-source single-phase rectifier.

rent can be controlled in the same phase. And the voltage and current are

$$
\begin{aligned}
& v_{s}=V_{s} \sin (\omega t) \\
& i_{a}=I_{a} \sin (\omega t)
\end{aligned}
$$

and we can get the input power

$p_{\text {in }}=v_{s} i_{a}-L_{a} \frac{d i_{a}}{d t} i_{a}=\frac{V_{s} I_{a}}{2}-\frac{V_{s} I_{a}}{2} \cos (2 \omega t)-\frac{w L_{a} I_{a}^{2}}{2} \sin (2 \omega t)$

so the dc component and the second harmonic component are,

$$
\begin{gathered}
p_{0}=\frac{V_{s} I_{a}}{2} \\
p_{2 \omega}=-\frac{V_{s} I_{a}}{2} \cos (2 \omega t)-\frac{\omega L_{a} I_{a}^{2}}{2} \sin (2 \omega t)
\end{gathered}
$$

The second harmonic voltage and current will flow through the quasi-Z-source network, the huge capacitor and inductor of the quasi-Z-source network are needed to make the second harmonic voltage and current ripple small. It costs much and takes much space. The input power of quasi-Z-source network is

$$
p_{p n}=(1-D) v_{p n} i_{p n}
$$

where D is the shoot-through duty cycle[12]. [13] has analyzed the second harmonic ripple of quasi-Z-source network, that is

$$
\begin{aligned}
& i_{L 1}=i_{L 2}=I_{L 1}+i_{L} \cos (2 \omega t-\lambda) \\
& v_{C 1}=V_{C 1}+v_{C} \sin (2 \omega t-\lambda)
\end{aligned}
$$

where $I_{L 1}$ and $V_{C 1}$ are the average current of inductor L1 and the average voltage of capacitor $\mathrm{C} 1$, respectively. The amplitudes of the second ripple of voltage and current are

$$
\begin{aligned}
& i_{L}=\frac{1-2 D}{\sqrt{\left[4 \omega^{2} L C-(1-2 D)^{2}+\left[\frac{4 \omega L I_{p n}(D-1)}{V_{p n}}\right]^{2}\right]}} \cdot \frac{V_{s} I_{a}}{2 V_{p n}} \\
& v_{C}=\frac{2 \omega L}{\sqrt{\left[4 \omega^{2} L C-(1-2 D)^{2}+\left[\frac{4 \omega L I_{p n}(D-1)}{V_{p n}}\right]^{2}\right]}} \cdot \frac{V_{s} I_{a}}{2 V_{p n}}
\end{aligned}
$$

source network.

When the parameters of the system have been designed, the quasi-Z-source network inductor and capacitor can be calculated by

$$
\begin{gathered}
L=\frac{v_{C}^{*}(1-2 D)}{2 \omega i_{L}^{*}} \\
C=\frac{(1-2 D)^{2}+\sqrt{(1-2 D)^{2}\left(\frac{V_{s} I_{a}}{2 V_{p n} i_{L}^{*}}\right)^{2}-\left[\frac{4 \omega L I_{p n}(D-1)}{V_{p n}}\right]^{2}}}{4 \omega^{2} L}
\end{gathered}
$$

where $v_{c}{ }_{c}$ is the voltage ripple amplitude, $i_{L}^{*}$ is the desired current ripple amplitude.

\section{B. Proposed System Design}

The APF circuit has no relationship with the quasi-Z-source network, so we only need to analyze APF single-phase rectifier at first. And the APF circuit is shown in Fig. 4.

Suppose the capacitor $\mathrm{C} 3$ and inductor $L_{3}$ to be

$$
v_{C 3}=V_{C 3} \sin (\omega t+\theta)
$$

$$
i_{C 3}=I_{C} \cos (\omega t+\theta)=\omega C_{3} V_{C 3} \cos (\omega t+\theta)
$$

We can get the power of the APF

$p_{A P F}=L_{3} \frac{d i_{C}}{d t} i_{C}+v_{C 3} i_{C}=\left(\frac{1}{2 \omega C_{3}}-\frac{\omega L_{3}}{2}\right) I_{C}^{2} \sin (2 \omega t+2 \theta)$

To eliminate sencond harmonic power in DC link, the power of APF should be

$$
p_{A P F}=p_{2 \omega}
$$

Submitting (5) and (14) into (15) yields

$$
\begin{gathered}
\frac{V_{s} I_{a}}{2}+\left(\frac{1}{2 \omega C_{3}}-\frac{\omega L_{3}}{2}\right) I_{C}^{2} \sin (2 \theta)=0 \\
\frac{\omega L_{a} I_{a}^{2}}{2}+\left(\frac{1}{2 \omega C_{3}}-\frac{\omega L_{3}}{2}\right) I_{C}^{2} \cos (2 \theta)=0
\end{gathered}
$$

The voltage of the capacitor C3 is controlled in the APF single-phase rectifier system, and the voltage and current of $\mathrm{C} 3$ can be get based on (16) and (17)

$$
\begin{gathered}
v_{C 3}=\sqrt{\frac{\sqrt{V_{s}^{2} I_{a}^{2}+\omega^{2} L_{a}^{2} I_{a}^{4}}}{\omega C_{3}-\omega^{3} L_{C} C_{3}^{2}}} \sin (\omega t+\theta) \\
i_{C}=\sqrt{\frac{\sqrt{V_{s}^{2} I_{a}^{2}+\omega^{2} L_{a}^{2} I_{a}^{4}}}{1 / \omega C_{3}-\omega L_{C}}} \cos (\omega t+\theta) \\
\theta=\frac{\pi}{2}+\frac{1}{2} \tan ^{-1}\left(\frac{V_{s}}{\omega L_{a} I_{a}}\right)
\end{gathered}
$$




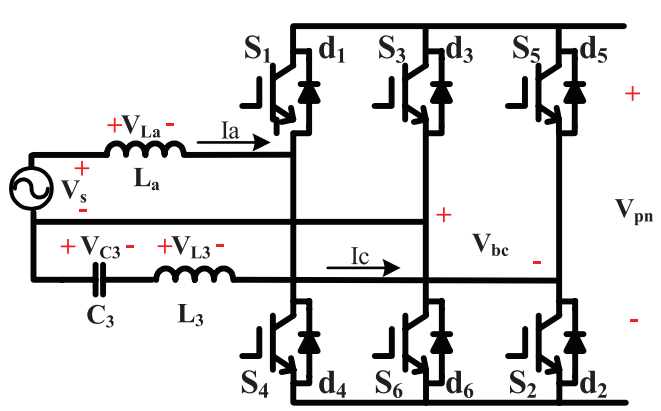

Fig. 4. The APF circuit.

When the voltage and current of the C3 satisfy the above conditions, the second harmonic power on DC link can be eliminated.

Because the second harmonic power ripple has been completely eliminated, the capacitor and inductor of the quasiZ-source network are designed only to limit the switching frequency ripple. Therefore, the value of capacitor and inductor can be smaller, and the value will be

$$
\begin{gathered}
L_{1}=L_{2}=\frac{D(1-D) V_{p n}}{2 f_{s}(1-2 D) I_{L 1} \delta_{\Delta i}} \\
C_{1}=C_{2}=\frac{I_{L 1} D(1-2 D)}{f_{s} V_{p n} \delta_{\Delta v}}
\end{gathered}
$$

where $\delta_{\Delta v}$ and $\delta_{\Delta i}$ are the ratio of peak to peak ripple.

\section{Control Strategy and Modulation}

\section{A. Control Strategy for APF}

In section two, we have got the reference voltage of the capacitor $\mathrm{C} 3$. Then we can control this voltage to make the system working with no second harmonic power.

First, we can get the transfer function

$$
G_{v}(s)=\frac{V_{C 3}}{V_{b c}}=\frac{1}{L_{3} C_{3} s^{2}+1}
$$

where $V_{b c}$ is the voltage between phase $\mathrm{B}$ and phase $\mathrm{C}$, and the equivalent resistance has been ignored. Because the proposed APF single-phase rectifier quasi-Z-source network is used as electric vehicle on-board integrated charger, the voltage and current sensors are enough to get the voltage and current of $\mathrm{C} 3$. Then we can use the $V_{C 3}$ and $I_{C}$ as the poles to get a very stable system. The capacitor voltage control system is shown in Fig. 5. When the $V_{b c}$ is obtained, it is easy to get the voltage of phase C. Then we can control the S2 and S5 to modulate the voltage.

\section{B. Modulation for Quasi-Z-Zource Network}

The modulation for the quasi-z-source network is shown in Fig. 6. In the paper [14], a novel modulation for soft-switching three-phase quasi-Z-source rectifier was proposed. The pro-

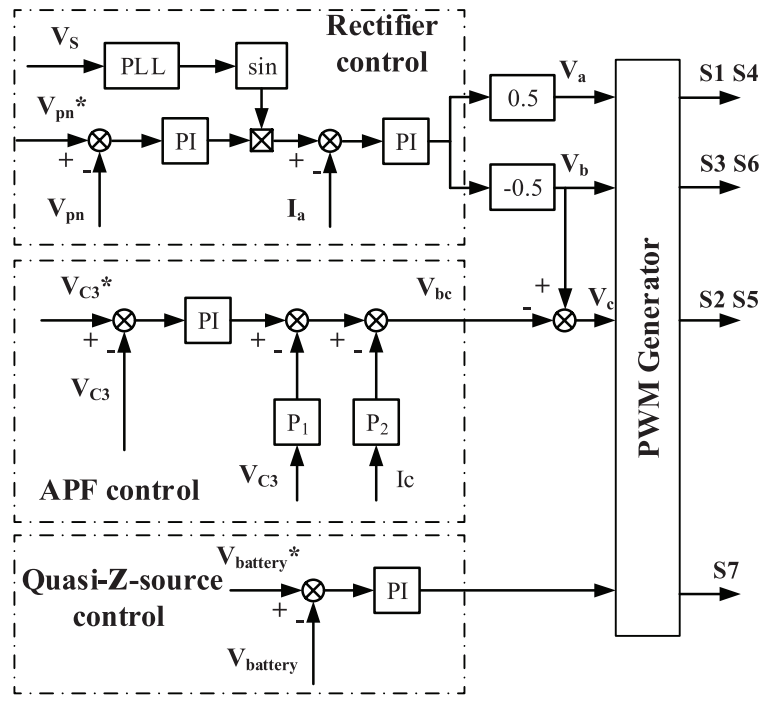

Fig. 5. The control strategy.

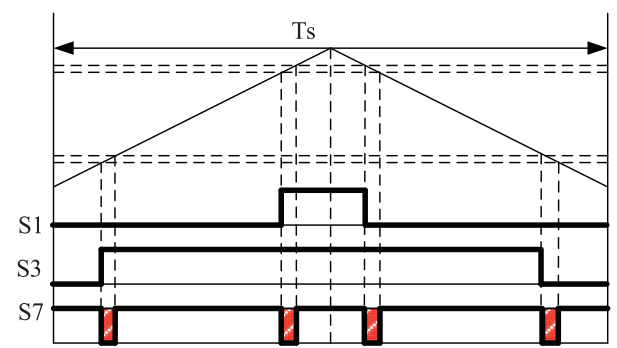

Fig. 6. The modulation for quasi-Z-source network.

posed modulation can be used in this APF single-phase quasi$\mathrm{Z}$-source system. When the S7 is turned off, the voltages across other switches (S1-S6) are clamped to zero. So the switches can be turned on or turned off under ZVS at the beginning of the system working in shoot-through state.

\section{Simulation and Experimental Verification}

The simulation and experimental results have been done to verify that the proposed APF single-phase quasi-Z-source rectifier can eliminate the second harmonic power.

A 750-W system has been designed with the parameters: $V_{s}=50 \mathrm{~V}, I_{a}=30 \mathrm{~A}, L_{a}=3 \mathrm{mH}, V_{p n}=190 \mathrm{~V}, R=30 \Omega, D=0.1$, $f_{s}=10 \mathrm{k}$. According to (10) and (11), the single-phase rectifier without APF needs quasi-Z-source impendence with $L=43$ $\mathrm{mH}$ and $C=780 \mathrm{uF}$ to make the second harmonic ripple smaller than $5 \%$. The inductors and capacitors are huge. While, based on (21) and (22), the capacitance and inductance are $C=26 \mathrm{uF}$ and $L=0.85 \mathrm{mH}$, respectively. In this paper, the values of $C=50 \mathrm{uF}$ and $L=1 \mathrm{mH}$ were used as the quasi-Z-source impendence.

\section{A. Simulation Results}

The traditional single phase quasi-Z-source rectifier suffers from the second harmonic ripple, so the voltage of $\mathrm{C} 2$ and the current of L1 have the second harmonic ripple. Fig. 7 shows the simulation result. The current of $\mathrm{L} 1$ and the voltage of $\mathrm{C} 2$ have 


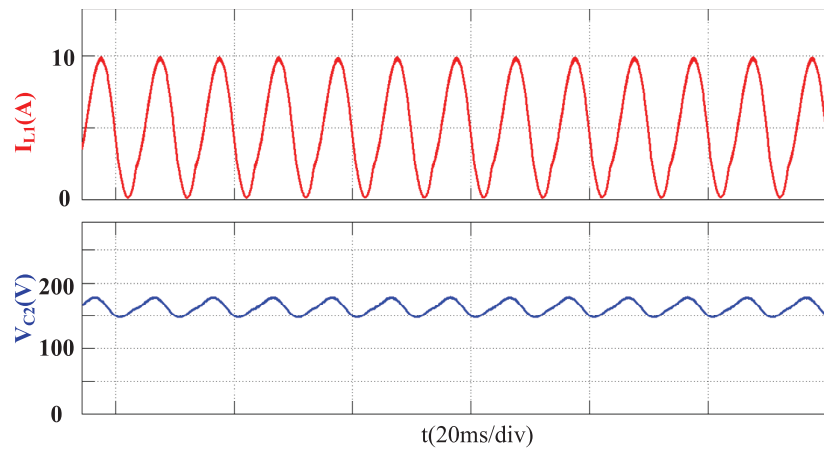

Fig. 7. Simulation results without APF: the inductor L1 current and the capacitor $\mathrm{C} 2$ voltage.

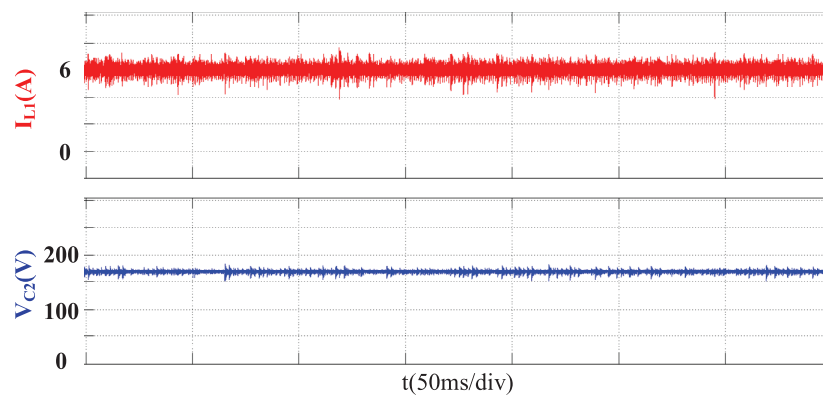

Fig. 8. Simulation results with APF: the inductor L1 current and the capacitor $\mathrm{C} 2$ voltage.

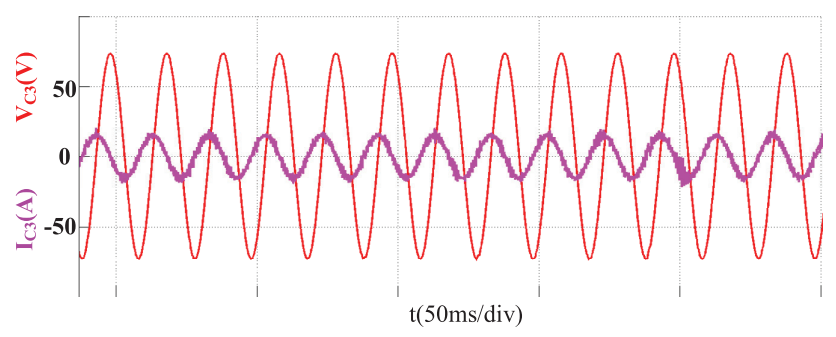

Fig. 9. Simulation results wih APF: the current and voltage of C3.

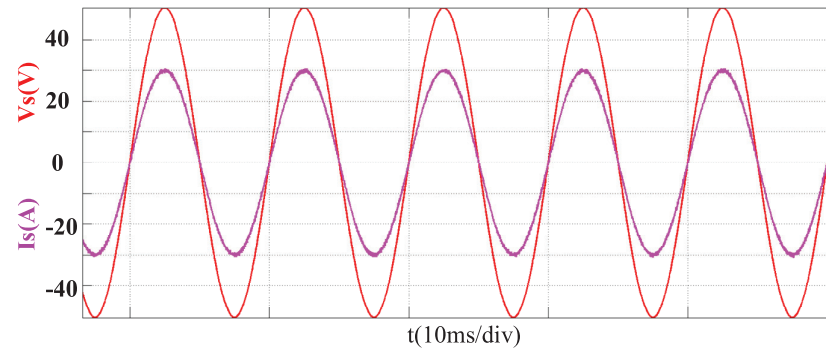

Fig. 10. Simulation results: grid-side voltage and grid-side current.

the large second harmonic ripple. Large capacitor and inductor are needed to suppress ripple. And when we use the proposed APF topology, the harmonic ripple can be eliminated, and the simulation result is shown in Fig. 8. From the simulation results, it can conclude that the APF topology absorbs all the second harmonic power.

The current and the voltage waveforms of the APF topology are shown in Fig. 9. And when the proposed APF single-phase

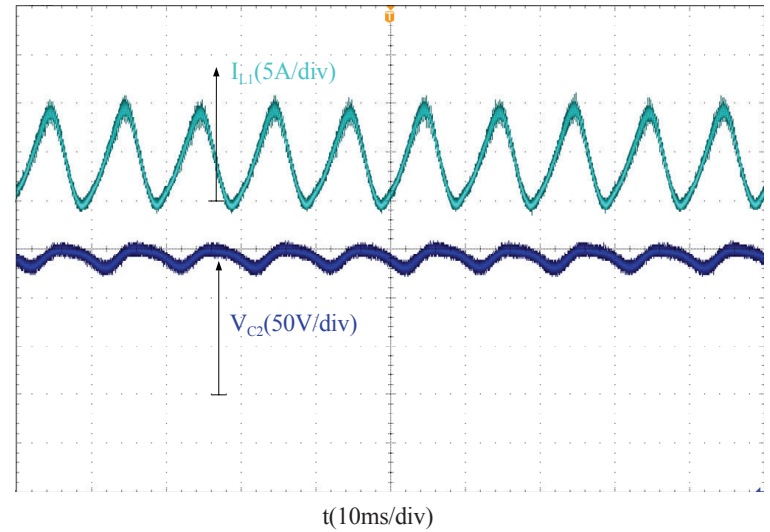

Fig. 11. Experimental results: L1 current and C2 voltage.

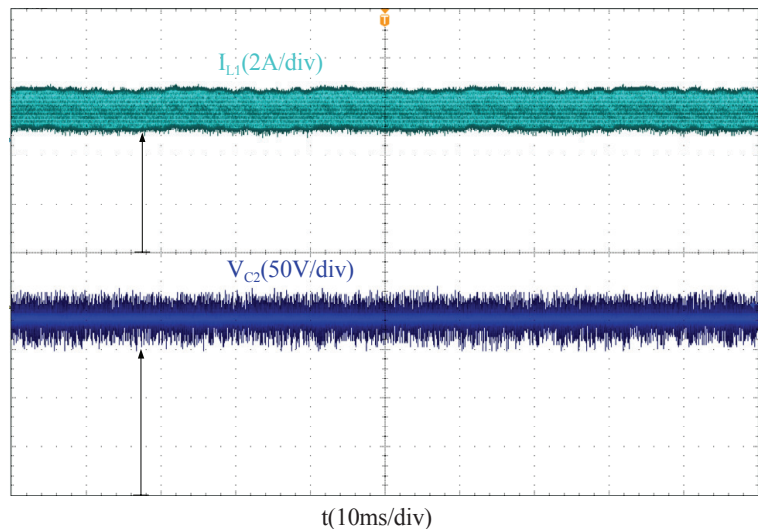

Fig. 12. Experimental results: L1 current and C2 voltage.

quasi-Z-source rectifier works, the grid-side current and voltage are with the same phase angle, as shown in Fig. 10. The efficiency of the system is high, and the harmonic of the grid-side current is small.

\section{B. Experimental Results}

Fig. 11 shows the experimental result of the quasi-Z-source single-phase rectifier without APF. From the Fig. 11, we can see that the current ripple of $\mathrm{L} 1$ and the voltage ripple of $\mathrm{C} 2$ are huge. And the waveforms are the same as the simulation result. The large current ripple will increase device loss and decrease the efficiency of the system. The APF topology is used to eliminate the second harmonic power, so the second harmonic current and voltage ripple can also be eliminated, the experimental result is shown in Fig. 12.

The experimental results of the current through APF and the voltage across $\mathrm{C} 3$ are shown in Fig. 13. Fig. 14 shows the gridside current and voltage waveforms.

\section{Conclusion}

This paper proposed an APF quasi-Z-source single-phase integrated on-board charger which can eliminate the second harmonic power on DC link. Compared with the quasi-Z-source single-phase rectifier without APF, the quasi-Z-source network 


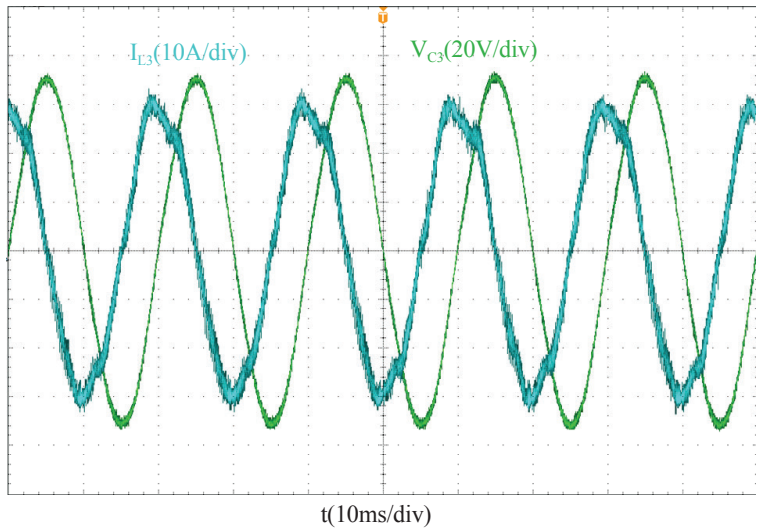

Fig. 13. Experimental results: $\mathrm{C} 3$ current and $\mathrm{C} 3$ voltage.

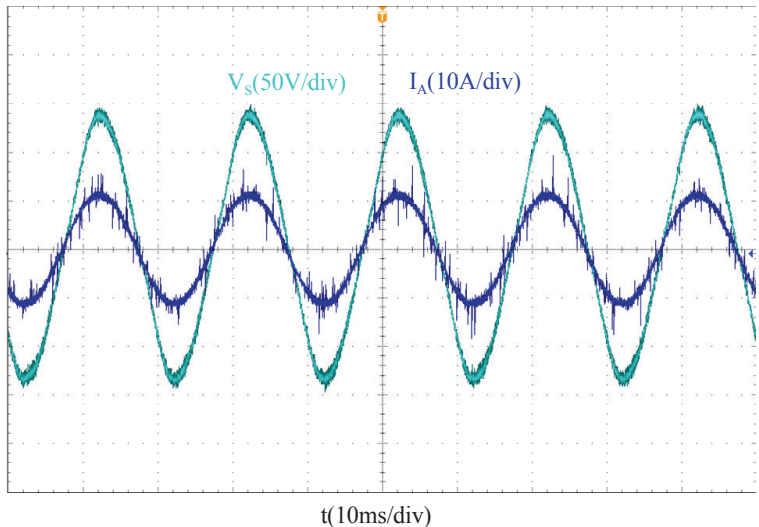

Fig. 14. Experimental results: grid-side current and grid-side voltage.

of the proposed system only need very small inductor and capacitor. The paper has provided the method how to design the parameters. Because this system can be used as an integrated on-board electric vehicle charger, it can make full use of the devices. Therefore, another advantage is that it saves much space and costs less. And a 750-W prototype has been designed. The simulation and experimental results have verified the theory of the proposed system.

\section{REFERENCES}

[1] S. Haghbin, S. Lundmark, M. Alakula, and O. Carlson, "Grid-Connected integrated battery chargers in vehicle applications: review and new solution," Industrial Electronics, IEEE Transactions on, vol. 60, no. 2, pp. 459-473, 2013

[2] T. Shimizu, T. Fujita, G. Kimura, and J. Hirose, "A unity power factor PWM rectifier with DC ripple compensation," IEEE Transactions on Industrial Electronics, vol. 44, no. 4, pp. 447-455, 1997.

[3] H. Li, K. Zhang, H. Zhao, S. Fan, and J. Xiong, "Active power decoupling for high-power single-phase PWM rectifiers," IEEE Transactions on Power Electronics, vol. 28, no. 3, pp. 1308-1319, 2013.

[4] M. Su, P. Pan, X. Long, Y. Sun, and J. Yang, "An active power-decoupling method for single-phase AC/DC converters," IEEE Transactions on Industrial Informatics, vol. 10, no. 1, pp. 461-468, 2014.

[5] W. Qi, H. Wang, X. Tan, G. Wang, and K. D. T. Ngo, "A novel active power decoupling single-phase PWM rectifier topology," in 2014 IEEE Applied Power Electronics Conference and Exposition - APEC 2014, pp. 89-95.

[6] T. Shimizu, Y. Jin, and G. Kimura, "DC ripple current reduction on a single-phase PWM voltage-source rectifier," IEEE Transactions on Industry Applications, vol. 36, no. 5, pp. 1419-1429, 2000.

[7] Y. Sun, Y. Liu, M. Su, W. Xiong, and J. Yang, "Review of active power decoupling topologies in single-phase systems," IEEE Transactions on Power Electronics, vol. 31, no. 7, pp. 4778-4794, 2016

[8] R. Wang et al., "A high power density single-phase PWM rectifier with active ripple energy storage," IEEE Transactions on Power Electronics, vol. 26, no. 5, pp. 1430-1443, 2011.

[9] K. H. Chao, P. T. Cheng, and T. Shimizu, "New control methods for single phase PWM regenerative rectifier with power decoupling function," in 2009 International Conference on Power Electronics and Drive Systems (PEDS), 2009, pp. 1091-1096.

[10] T. Larsson and S. Ostlund, "Active DC link filter for two frequency electric locomotives," in 1995 International Conference on Electric Railways in a United Europe, 1995, pp. 97-100.

[11] Y. Yu, Q. Zhang, B. Liang, and S. Cui, "Single-phase Z-Source inverter: Analysis and low-frequency harmonics elimination pulse width modulation," in 2011 IEEE Energy Conversion Congress and Exposition, 2011, pp. 2260-2267.

[12] D. Sun et al., "Modeling, impedance design, and efficiency analysis of quasi-Z-source module in cascaded multilevel photovoltaic power system," IEEE Transactions on Industrial Electronics, vol. 61, no. 11, pp. 6108-6117, 2014.

[13] B. Ge et al., "An active filter method to eliminate DC-side low-frequency power for a single-phase quasi-Z-source inverter," IEEE Transactions on Industrial Electronics, vol. 63, no. 8, pp. 4838-4848, 2016.

[14] Q. Zhang, T. Na, L. Song, and S. Dong, "A novel modulation for soft-switching three-phase quasi-Z-source rectifier without auxiliary circuit," IEEE Transactions on Industrial Electronics, vol. 65, no. 6, pp. 5157-5166, 2018.

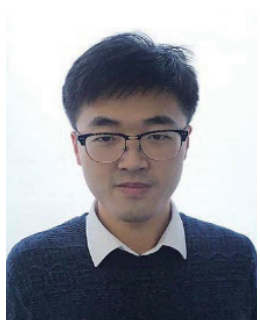

Tuopu Na received the B.S. and M.S. degree in Electrical Engineering from the Harbin Institute of Technology, Harbin, China, in 2012 and in 2014, respectively. He is current a Ph.D. in the school of electrical engineering, Harbin Institute of Technology, Harbin, China. His research interests include electric vehicle integrated charger, Z-source converter/inverter, etc.

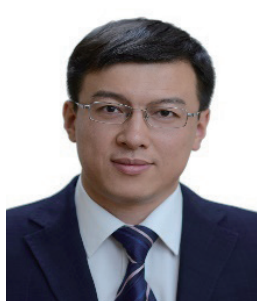

Qianfan Zhang was born in Heilongjiang province, China. He received B.S. and Ph.D. from the Harbin Institute of Technology, Harbin, China, in 1999 and 2004, respectively, both in electrical engineering. In 1999, he joined department of electrical engineering in Harbin Institute of Technology as a faculty. He is professor since 2010. His research interesting includes electric machine and drives, power electronics applied on EV, HEV, integrated charging system, and wireless power transfer system.

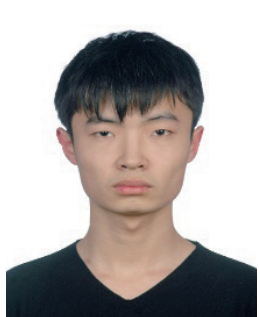

Jiaqi Tang received the B.S. degree in electrical engineering from Harbin Institute of Technology, Harbin, China, where he is currently working toward the Ph.D. degree. His research interests include wireless power transfer.

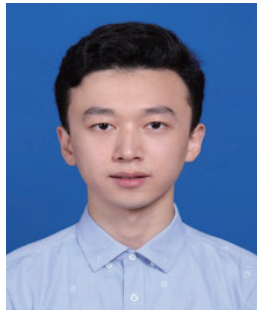

Jinxin Wang was born in Chongqing, China, in 1996. He received the B.Sc degree in electrical engineering from the Harbin Institute of Technology, Harbin, China in 2018, where he is currently pursuing the M.Sc degree in electrical engineering. His current research interests include power electronics and electric machine drives, particularly the thermal behaviors of those devices. 